\title{
Gridded Assessment of Ecological Vulnerability in Loess Hilly Region of Western Henan Province, China
}

\author{
Pei Zhao ${ }^{{ }^{*}}$, Chi Zhang ${ }^{2}$, Zhiwei Sheng ${ }^{3}$, Jingyan $\mathrm{Chu}^{3}$ \\ ${ }^{1}$ College of Surveying and Geo-informatics, North China University of Water Resources and Electric \\ Power, Zhengzhou, 450045, China \\ ${ }^{2}$ College of Geosciences and Engineering, North China University of Water Resources and Electric Power, \\ Zhengzhou, 450045, China \\ ${ }^{3}$ The Fourth Exploration Team, Coal Geology Bureau of Henan Province, Zhengzhou, 450016, China \\ *Corresponding author.
}

\begin{abstract}
:
Based on meteorological, remote sensing, socio-economic data in 2000 and 2019 and PSR (Pressure-State-Response) evaluation model, an evaluation index system of ecological vulnerability in the loess hilly region of western Henan Province was constructed. Using spatial principal component analysis and spatial autocorrelation analysis, the ecological vulnerability of the study area was quantitatively evaluated with $2 \mathrm{~km} \times 2 \mathrm{~km}$ grid as the research scale, and the driving force of ecological vulnerability was determined by principal component load matrix analysis. The results show that: (1) The ecological environment in the Loess hilly region of western Henan showed a deteriorating trend from 2000 to 2019. (2) The vulnerability degree of the ecological environment in different counties was obviously different, and the vulnerability degree in the main city and suburbs was always at an extreme vulnerable level, while other regions showed different trends. (3) From 2000 to 2019, the ecological vulnerability had significant positive correlation and aggregation characteristics. The H-H clustering areas were mainly distributed in extreme vulnerable areas, while the L-L clustering areas are mainly related to negligible and light vulnerable areas. (4) The main driving factors of ecological vulnerability in the loess hilly region of western Henan are elevation, slope, terrain relief, degree of land use, annual mean precipitation, NDVI, annual mean temperature, land use type and urbanization rate.
\end{abstract}

Keywords: Ecological vulnerability, Loess hilly region, Western Henan Province. 


\section{INTRODUCTION}

With the global socio-economic development and intense human activities, ecological environment problems such as climate warming, sharp decline in biodiversity and soil erosion have become increasingly prominent, and ecological vulnerability has become a research hotspot in the sustainable development of human society [1]. Ecological vulnerability assessment is aimed at the ecological environment situation in a specific region, analyzing the change law of ecological vulnerability, and clarifying the change mechanism and driving factors of ecological vulnerability. The results can provide a basis for ecological environment protection and restoration. At present, scholars have used a variety of methods [2-5] to evaluate ecological vulnerability in different scales [6-9] and different geomorphic types [10-13]. But the current research also has some problems, such as short research time span, coarse granularity of evaluation units, incomplete coverage of typical case areas, relatively single evaluation index and so on.

In view of the deficiency of current research, this paper takes the high-density grid as the evaluation unit, and selects the Loess hilly region in the west of Henan Province as the research object. Because of the inherent characteristics of Loess, the ecological environment in the Loess hilly region is extremely vulnerable. In recent years, with the rapid development of regional economy, the city scale has been expanding, resulting in a series of ecological environment problems such as soil erosion, environmental pollution and land resource shortage [14]. This paper is based on the spatial remote sensing technology and the actual situation of the ecological environment in the study area. Taking multi-factors into consideration and using PSR (pressure-state-response) evaluation model, an evaluation system of ecological vulnerability in the Loess hilly region of western Henan was constructed by selecting 15 evaluation factors, and the spatial principal component analysis method was used, combined with the global Moran's I index and LISA cluster diagram. The ecological vulnerability in the study area from 2000 to 2019 was dynamically and quantitatively evaluated, and then the spatial and temporal distribution characteristics and driving forces of ecological vulnerability in the Loess hilly region of western Henan were revealed, which provided theoretical basis for ecological restoration in western Henan.

\section{STUDY AREA}

The study area is located in the hilly region of western Henan $\left(110^{\circ} 21^{\prime}-113^{\circ} 30^{\prime} \mathrm{E}\right.$, $33^{\circ} 32^{\prime}-35^{\circ} 11^{\prime}$ N, Fig 1), including Gongyi in Zhengzhou, Yanshi, Xigong, Jili, Laocheng, Chanhe, Mengjin, Yanshi, Luolong, Yichuan, Xinan, Jianxi, Yiyang in Luoyang, Hubin, Yima, Mianchi, Shanzhou and Lingbao in Sanmenxia. The loess hilly region of western Henan 

altitude is $85 \mathrm{~m}$, and the highest altitude is $2192 \mathrm{~m}$. This area belongs to temperate semi-humid and semi-arid climate, with annual average temperature of $14.6^{\circ} \mathrm{C}$ and average precipitation of about $643.4 \mathrm{~mm}$. The main rivers are Luo River and Yi River, in Yanshi after merging into the Yellow River, and are the largest first-class tributaries in the lower middle reaches of the Yellow River. In the region, the topography is undulating and complex, with diverse land use types. The landform types mainly include mountains, hills and plains.

\subsection{Data Sources}

\section{RESEARCH METHODS}

Landsat remote sensing image data in 2000 and 2019 with resolution of 30m were selected as remote sensing data. Based on this data, land use type data was constructed by man-machine interpretation under ArcGIS and ENVI software platform. Meteorological data came from the China Meteorological Data Service Centre, including the average annual precipitation and average annual temperature data of western Henan in 2000 and 2019. The normalized difference vegetation index (NDVI) in 2000 and 2019 was synthesized from Landsat-NDVI data with resolution of $30 \mathrm{~m}$ in the United States Geological Survey, and the socio-economic data came from Henan Statistical Yearbook, Zhengzhou Yearbook and Luoyang Yearbook in 2001 and 2020. Combined with the actual situation of western Henan and after repeated verification and testing, the study area was divided into $2 \mathrm{~km} \times 2 \mathrm{~km}$ grids in this paper so as to ensure the accuracy of data. Geometric registration and resampling were carried out on all data before evaluation and analysis. To refine the 15 evaluation indexes to the grid unit as much as possible, the data with partial missing spatial attributes in data processing were obtained indirectly by the data acquisition technology based on the existing research results (Fig 1).
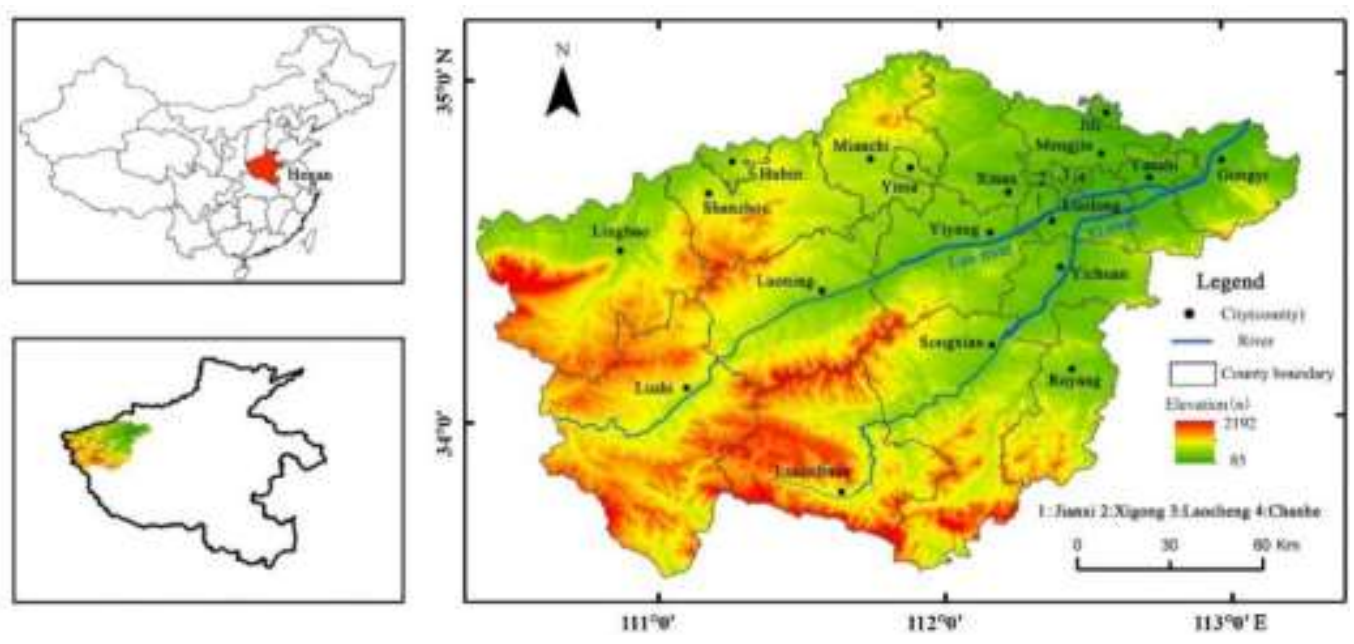


\subsection{Data Preprocessing}

Topographic data: based on remote sensing data, the data of elevation, slope and topographic relief in the study area were obtained through ArcGIS 10.2 platform.

Landscape index data: the interpreted land use data calculated by using the software of Fragstats 4.2 was taken as the object.

Data of land use degree: the land use degree comprehensively reflects the land use degree of a certain area [15], and the calculation method is shown in Formula (1):

$$
\mathrm{L}_{a}=100 \times \sum_{i=1}^{n} M_{i} \times B_{i}
$$

$L a$ is the degree of land use; $M_{i}$ is the grade $i$ land use degree classification index; $B_{i}$ is the area ratio of grade $i$ land use degree classification.

Meteorological data: the annual average temperature and precipitation was based on the meteorological station data in the surrounding areas of the study area, and the inverse distance weighted interpolation method was used for spatial deterministic interpolation to realize data spatialization.

Socio-economic data: population density refers to the total population/area of each county and city; per capita cultivated land refers to the total cultivated land area/population of each evaluation unit; Per capita GDP refers to the regional GDP/total population of each county (city); urbanization rate refers to the urban land area/total area of each evaluation unit.

\subsection{Evaluation Index System}

Ecological vulnerability assessment is based on the construction of a scientific and reasonable index system, and the principles of scientificalness, dominance, operability and purposiveness should be followed in the accurate selection of evaluation factors affecting vulnerability. By referring to the relevant research results at home and abroad [16,17], Ecological Sensitivity-Ecological Recovery-Ecological Pressure Model (SRP) evaluation model was introduced to determine the index system is determined according to local conditions. Finally, five criteria layers were determined from the three target levels, including 
Article History: Received: 10 May 2021 Revised: 20 June 2021 Accepted: 18 July 2021 Publication: 31 August 2021 pressure, resilience and sensitivity, and 15 evaluation factors were selected to construct the evaluation index system of ecological vulnerability in western Henan. According to the impact on the ecological vulnerability of western Henan, the selected indexes were divided into positive and negative indexes, as shown in TABLE I.

TABLE I. Ecological vulnerability evaluation index system in western Henan.

\begin{tabular}{|c|c|c|c|}
\hline $\begin{array}{l}\text { TARGET } \\
\text { LAYER }\end{array}$ & $\begin{array}{l}\text { CRITERIA } \\
\text { LAYER }\end{array}$ & INDICATOR LAYER & $\begin{array}{l}\text { ATTRIBUTE } \\
\mathbf{S} \\
\end{array}$ \\
\hline \multirow{8}{*}{$\begin{array}{l}\text { Ecological } \\
\text { sensitivity }\end{array}$} & Terrain factor & Elevation/m & Forward \\
\hline & & Slope $/\left(^{\circ}\right)$ & Forward \\
\hline & & Terrain relief $/\left(^{\circ}\right)$ & Forward \\
\hline & Surface factor & Landscape diversity & Negative \\
\hline & & Landscape fragmentation & Forward \\
\hline & & Land use type & Qualitative \\
\hline & $\begin{array}{l}\text { Meteorological } \\
\text { factor }\end{array}$ & Annual mean temperature & Negative \\
\hline & & $\begin{array}{l}\text { Annual mean } \\
\text { precipitation } / \mathrm{mm}\end{array}$ & Forward \\
\hline $\begin{array}{l}\text { Ecological } \\
\text { recovery }\end{array}$ & Vegetation factor & $\begin{array}{l}\text { Normalized difference } \\
\text { vegetation index }\end{array}$ & Negative \\
\hline \multirow[t]{6}{*}{$\begin{array}{l}\text { Ecological } \\
\text { pressure }\end{array}$} & Social factors & $\begin{array}{l}\text { Population density } \\
\left(\text { person } / \mathrm{km}^{2}\right)\end{array}$ & Forward \\
\hline & & $\begin{array}{c}\text { Per capita GDP } \\
(100,000 / \text { person })\end{array}$ & Forward \\
\hline & & $\begin{array}{l}\text { Per capita cultivated land } \\
\text { (mu/person) }\end{array}$ & Negative \\
\hline & & Urbanization rate $/ \%$ & Forward \\
\hline & & Degree of land use/\% & Forward \\
\hline & & $\begin{array}{l}\text { Proportion of the second } \\
\text { industry } / \%\end{array}$ & Forward \\
\hline
\end{tabular}

3.4 Standardization of Index Data 
Because of the different properties and dimensions of each evaluation index, this study adopted range method and hierarchical assignment method to standardize all indexes.

Range method: see formulas (2) and (3) for the calculation method:

Positive correlation:

$$
V_{i j}=\frac{A_{i j}-A_{j \min }}{A_{j \max }-A_{j \min }} \times 10
$$

Negative correlation:

$$
A_{i j}=\frac{A_{i j}-A_{j \min }}{A_{j \max }-A_{j \min }} \times 10
$$

$V_{i j}$ is the result of standardization of indexes, with a range of $0 \sim 10$, and $A_{i j}$ is the index value of $i$ index in evaluation unit $j ; A_{\text {imin }}$ is the minimum value of $i$ index in all evaluation units, and $A_{\text {imax }}$ is the maximum value of $i$ index in all evaluation units

Graded assignment method: for qualitative indexes, according to the actual characteristics of land use in western Henan and combined with relevant research data [10], quantitative assignment was carried out according to the graded assignment method, as shown in TABLE II.

TABLE II. Standardized value assignment.

\begin{tabular}{cccccc}
\hline \multirow{2}{*}{ INDEX } & \multicolumn{5}{c}{ GRADING INDEX } \\
\cline { 2 - 5 } & 2 & 4 & 6 & 8 & 10 \\
\hline $\begin{array}{c}\text { Land use } \\
\text { type }\end{array}$ & $\begin{array}{c}\text { Woodland, water } \\
\text { body }\end{array}$ & $\begin{array}{c}\text { Grassland and } \\
\text { wetland }\end{array}$ & Farmland & $\begin{array}{c}\text { Construction } \\
\text { land }\end{array}$ & $\begin{array}{c}\text { Bare } \\
\text { land }\end{array}$ \\
\hline
\end{tabular}

\subsection{Ecological Vulnerability Assessment Method}

In this paper, the comprehensive index model of ecological vulnerability was constructed to quantitatively evaluate the ecological vulnerability in loess hilly region of western Henan. To shield the correlation, fuzziness and overlap among evaluation indexes, and determine the 

reorganization and dimension reduction of evaluation data information, transform multiple variables into a few comprehensive indexes with extremely low correlation and determine the contribution rate of indexes on the premise of minimum loss of evaluation index information value. Supported by ArcGIS10.2 and IBM SPSS Statistics19.0, the spatial principal component analysis was used to analyze 15 evaluation indexes. According to the cumulative factor contribution rate of more than $80 \%$, four principal component factors were determined (TABLE III). Based on the spatial principal component analysis, the ecological vulnerability index (EVI) was calculated. The model is as follows:

$$
E V I=\beta_{1} Y_{1}+\beta_{2} Y_{2}+\beta_{3} Y_{3}+\cdots+\beta_{n} Y_{n}
$$

$E V I$ is the ecological vulnerability index of the evaluation unit of the study area; $\beta_{n}$ is the nth principal component, and $Y_{n}$ is the contribution rate corresponding to the nth principal component.

TABLE III. Eigenvalue, contribution rate and cumulative contribution rate of principal components.

\begin{tabular}{ccrrrr}
\hline \multirow{2}{*}{ YEAR } & \multirow{2}{*}{$\begin{array}{c}\text { COEFICIENTS OF PRINCIPAL } \\
\text { COMPONENT }\end{array}$} & \multicolumn{4}{c}{ PRINCIPAL COMPONENT } \\
\cline { 3 - 6 } 2000 & Eigenvalue $\lambda / \%$ & 7.381 & 1.999 & 1.701 & 1.137 \\
& Contribution $/ \%$ & 49.205 & 13.327 & 11.339 & 7.581 \\
& Cumulative contribution $/ \%$ & 49.659 & 62.986 & 74.325 & 81.906 \\
2019 & Eigenvalue $\lambda / \%$ & 7.778 & 1.999 & 1.355 & 1.107 \\
& Contribution $/ \%$ & 51.852 & 13.325 & 9.035 & 7.378 \\
& Cumulative contribution $/ \%$ & 51.852 & 65.177 & 74.212 & 81.590 \\
\hline
\end{tabular}

3.6 Classification and Grading of Ecological Vulnerability

To fully grasp the ecological vulnerability of loess hilly region of western Henan, referring to the existing ecological vulnerability evaluation standards at home and abroad [2,18], and according to the specific characteristics of the western Henan, the ecological vulnerability of western Henan was divided into five grades by combining natural breakpoints with actual 
Article History: Received: 10 May 2021 Revised: 20 June 2021 Accepted: 18 July 2021 Publication: 31 August 2021 conditions, namely negligible, light, medium, strong and extreme vulnerability, as shown in TABLE IV.

\section{TABLE IV. Classification standard and its ecological characteristics of ecological vulnerability.}

\begin{tabular}{ccc}
\hline VULNERABILITY & STANDARDIZED VALUE OF \\
LEVEL & LEVEL & $\begin{array}{c}\text { STANOLOGICAL VULNERABILITY } \\
\text { ECOLOGINEX }\left(\boldsymbol{S}_{\boldsymbol{E V I I}}\right)\end{array}$ \\
\hline Negligible & I & $\leq 2.333$ \\
Light & II & $2.333 \sim 3.914$ \\
Medium & III & $3.914 \sim 5.331$ \\
Strong & IV & $5.331 \sim 6.325$ \\
Extreme & V & $>6.325$ \\
\hline
\end{tabular}

\subsection{Comprehensive Index of Ecological Vulnerability}

To facilitate the measurement and comparison of ecological vulnerability index, it needs to be standardized. The standardized calculation method is as follows:

$$
S_{\mathrm{EVI}}=\frac{\mathrm{EVI}-\mathrm{EVI}_{\min }}{\mathrm{EVI}_{\max }-\mathrm{EVI}_{\min }} \times 10
$$

$S_{E V I}$ is the standardized value of ecological vulnerability index, with a value ranging from 0 to $10, E V I$ is the actual value of ecological vulnerability index; $E V I_{\max }$ is the maximum value of ecological vulnerability index of all evaluation units; $E V I_{\min }$ is the minimum value of ecological vulnerability index of all evaluation units.

\subsection{Spatial Autocorrelation}

Spatial autocorrelation analysis is to test whether a certain element is associated with its adjacent range and the degree of association. Global spatial autocorrelation can express the spatial dependence of an element in the whole range, while local spatial autocorrelation can express the similarity between a sampling unit and its neighboring units, which can directly reflect the spatial aggregation characteristics of an element. In this paper, global and local Moran's I index were selected. With the support of GeoDa software platform, and based on the grid scale, the spatial differences and agglomeration characteristics of the comprehensive index 
Article History: Received: 10 May 2021 Revised: 20 June 2021 Accepted: 18 July 2021 Publication: 31 August 2021 of ecological vulnerability in 2000 and 2019 were analyzed respectively. On the basis of calculating local Moran's I index, spatial clustering was carried out to obtain spatial LISA clustering diagram. Within the $95 \%$ confidence interval, the ecological vulnerability was further divided into five different types, See TABLE V for details:

TABLE V. The connotation of different LISA clustering models.

\begin{tabular}{|c|c|}
\hline $\begin{array}{l}\text { CLUSTERING } \\
\text { TYPES }\end{array}$ & CONNOTATION \\
\hline High-High $(\mathrm{H}-\mathrm{H})$ & $\begin{array}{c}\text { The regional ecological vulnerability and the surrounding level are } \\
\text { both high spatial agglomeration characteristics }\end{array}$ \\
\hline High-Low (H-L) & $\begin{array}{c}\text { The fragility of the ecological environment in the region itself is } \\
\text { high, but the spatial agglomeration characteristics of the } \\
\text { surrounding areas are low }\end{array}$ \\
\hline Low-High (L-H) & $\begin{array}{l}\text { The fragility of the regional ecological environment is low, but the } \\
\text { surrounding areas have high spatial agglomeration characteristics }\end{array}$ \\
\hline Low-Low (L-L) & $\begin{array}{l}\text { Spatial agglomeration characteristics with low ecological } \\
\text { vulnerability and low peripheral level in the region }\end{array}$ \\
\hline No significant & There is no obvious spatial agglomeration feature \\
\hline
\end{tabular}

\section{RESULTS}

\subsection{Analysis on the Difference of Ecological Vulnerability in Western Henan}

According to the results of assessment (TABLE VI, TABLE VII) and spatial distribution map (Fig 2) in western Henan from 2000 to 2019, the negligible, light and medium vulnerable areas in western Henan in 2000 accounted for $23.49 \%, 23.20 \%$ and 22.43 respectively. They were mainly concentrated in Luanchuan, Lushi, Songxian, Ruyang, south Lingbao, south Shanzhou and north Xinan in the middle and south of the study area. Strong and extreme vulnerable areas were relatively small, accounting for $14.98 \%$ and $15.90 \%$ of the study area, mainly distributed in the northeast and northwest in western Henan. These areas were cultivated land and urban center areas with high population density and strong influence of human activities. After 2000, with the gradual acceleration of urbanization in western Henan, the urban rate had been continuously improved. With the serious interference of human activities on the ecological environment, the ecological environment in the study area had further deteriorated. In 2019, the negligible, light and medium vulnerable areas accounted for $23.18 \%, 20.48 \%$ and $20.76 \%$ of the study area, respectively, which decreased slightly 
Article History: Received: 10 May 2021 Revised: 20 June 2021 Accepted: 18 July 2021 Publication: 31 August 2021 compared with 2000. Strong and extreme vulnerable areas accounted for $15.86 \%$ and $19.72 \%$ of the study area, respectively, which increased to a certain extent compared with 2000 . On the whole, the extreme vulnerable areas were mainly distributed in the main urban area and its surrounding areas, the strong and medium vulnerable areas, were mainly distributed in the loess hilly areas. The light and medium vulnerable areas were distributed in the southern and northern mountainous areas. The ecological environment in loess hilly region of western Henan showed a deteriorating trend as a whole.

TABLE VI. The results of ecological vulnerability evaluation in western Henan from 2000 to 2019.

\begin{tabular}{|c|c|c|c|c|c|c|}
\hline \multirow[b]{2}{*}{$\begin{array}{c}\text { VULNERABILIT } \\
\text { Y } \\
\text { LEVEL }\end{array}$} & \multicolumn{3}{|c|}{2000} & \multicolumn{3}{|c|}{2019} \\
\hline & $\begin{array}{l}\mathrm{Gr} \\
\mathrm{id}\end{array}$ & $\begin{array}{l}\text { Area/k } \\
\mathrm{m}^{2}\end{array}$ & $\begin{array}{c}\text { Percentage } \\
\text { of total } \\
\text { area } / \%\end{array}$ & $\begin{array}{l}\mathrm{Gr} \\
\mathrm{id}\end{array}$ & $\begin{array}{l}\text { Area/k } \\
\mathrm{m}^{2}\end{array}$ & $\begin{array}{l}\text { Percenta } \\
\text { ge } \\
\text { of total } \\
\text { area }\end{array}$ \\
\hline Negligible & $\begin{array}{c}14 \\
42\end{array}$ & 5768 & 23.20 & $\begin{array}{c}12 \\
78\end{array}$ & 5112 & 20.48 \\
\hline Light & $\begin{array}{l}14 \\
66\end{array}$ & 5864 & 23.49 & $\begin{array}{c}14 \\
47\end{array}$ & 5788 & 23.18 \\
\hline Medium & $\begin{array}{l}14 \\
00\end{array}$ & 5600 & 22.43 & $\begin{array}{l}12 \\
96\end{array}$ & 5184 & 20.76 \\
\hline Strong & $\begin{array}{l}93 \\
5\end{array}$ & 3740 & 14.98 & $\begin{array}{l}99 \\
0\end{array}$ & 3960 & 15.86 \\
\hline Extreme & $\begin{array}{l}99 \\
7\end{array}$ & 3988 & 15.90 & $\begin{array}{c}12 \\
29\end{array}$ & 4916 & 19.72 \\
\hline Total & $\begin{array}{l}62 \\
40\end{array}$ & 24960 & 100 & $\begin{array}{l}62 \\
40\end{array}$ & 24960 & 100 \\
\hline
\end{tabular}
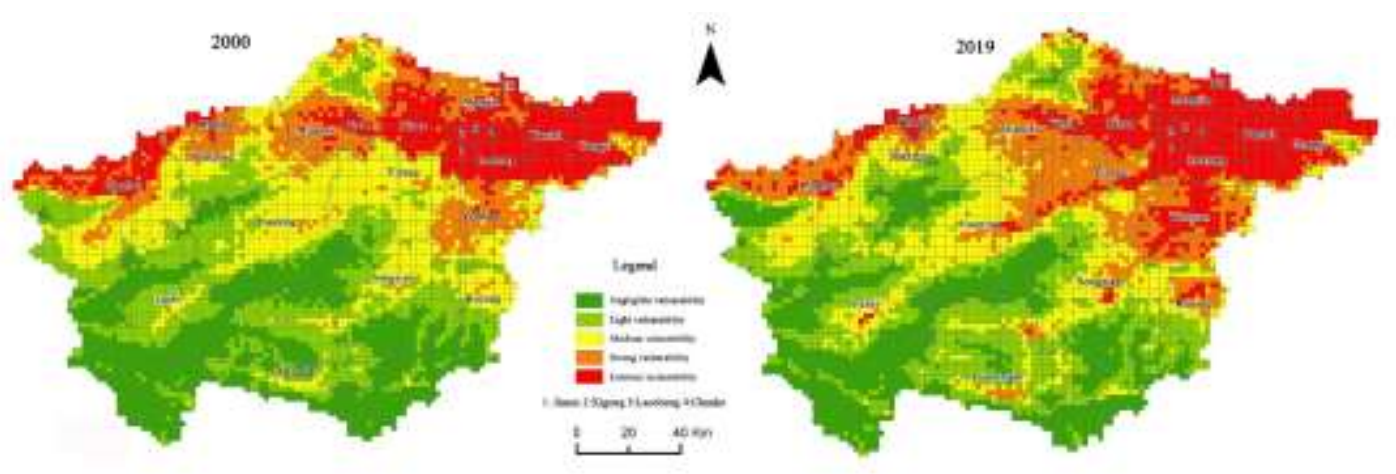
Fig 2: Distribution of ecological Vulnerability Rating in western Henan from 2000 to 2019

From 2000 to 2019, the degree of vulnerability of ecological environment in different counties varies greatly. Xigong, Geely, Laocheng, Chanhe, Jianxi, Gongyi, Yima, Yanshi, Luolong, Xinan and Hubin, which are located in the main city and suburbs, have always been extreme vulnerable. However, Luanchuan, Songxian and Lushi, which are located in the southern mountainous areas, are always light and medium vulnerable areas. Other regions are changing in different directions. Yichuan and Mengjin, located in the Loess hilly area around the main city, changed from strong vulnerable area to extreme vulnerable area. Yiyang changed from medium vulnerable area to strong vulnerable area, and Ruyang changed from light vulnerable area to medium vulnerable area. It can be seen that with the gradual acceleration of urbanization and the intensification of human activities, the vulnerable degree of ecological environment in these areas is gradually deepening. In recent years, the vulnerable degree of ecological environment in Lingbao, Shanzhou and Mianchi, where large-scale projects of returning farmland to forests are carried out, tends to decrease. Among them, the extreme vulnerable areas in Lingbao and Mianchi decreased from 21.97\% and $10.31 \%$ in 2000 to $8.29 \%$ and $7.25 \%$ in 2019 , respectively.

To sum up, from 2000 to 2019, the ecological environment in the study area showed a deteriorating trend as a whole. The degree of vulnerability of ecological environment in different counties varies greatly, showing a trend of change in different directions.

TABLE VII. Assessment results of ecological vulnerability in different counties from 2000 to $2019 / \%$.

\begin{tabular}{|c|c|c|c|c|c|c|c|c|c|c|}
\hline \multirow{2}{*}{ COUNTY } & \multicolumn{2}{|c|}{$\begin{array}{c}\text { MICRO } \\
\text { DEGREE }\end{array}$} & \multicolumn{2}{|c|}{ LIGHT } & \multicolumn{2}{|c|}{ MEDIUM } & \multicolumn{2}{|c|}{ STRONG } & \multicolumn{2}{|c|}{ EXTREME } \\
\hline & 2000 & 2019 & 2000 & 2019 & 2000 & 2019 & 2000 & 2019 & 2000 & 2019 \\
\hline Xigong & 0.00 & 0.00 & 0.00 & 0.00 & 0.00 & 0.00 & 0.00 & 0.00 & $\begin{array}{c}100.0 \\
0\end{array}$ & $\begin{array}{c}100.0 \\
0\end{array}$ \\
\hline ChanHe & 0.00 & 0.00 & 0.00 & 0.00 & 0.00 & 0.00 & 0.00 & 0.00 & $\begin{array}{c}100.0 \\
0\end{array}$ & $\begin{array}{c}100.0 \\
0\end{array}$ \\
\hline Laocheng & 0.00 & 0.00 & 0.00 & 0.00 & 0.00 & 0.00 & 0.00 & 0.00 & $\begin{array}{c}100.0 \\
0\end{array}$ & $\begin{array}{c}100.0 \\
0\end{array}$ \\
\hline $\mathrm{JiLi}$ & 0.00 & 0.00 & 0.00 & 0.00 & 0.00 & 0.00 & 0.00 & 0.00 & $\begin{array}{c}100.0 \\
0\end{array}$ & $\begin{array}{c}100.0 \\
0\end{array}$ \\
\hline Jianxi & 0.00 & 0.00 & 0.00 & 0.00 & 8.70 & 2.17 & 6.52 & 4.35 & 84.78 & 93.48 \\
\hline
\end{tabular}




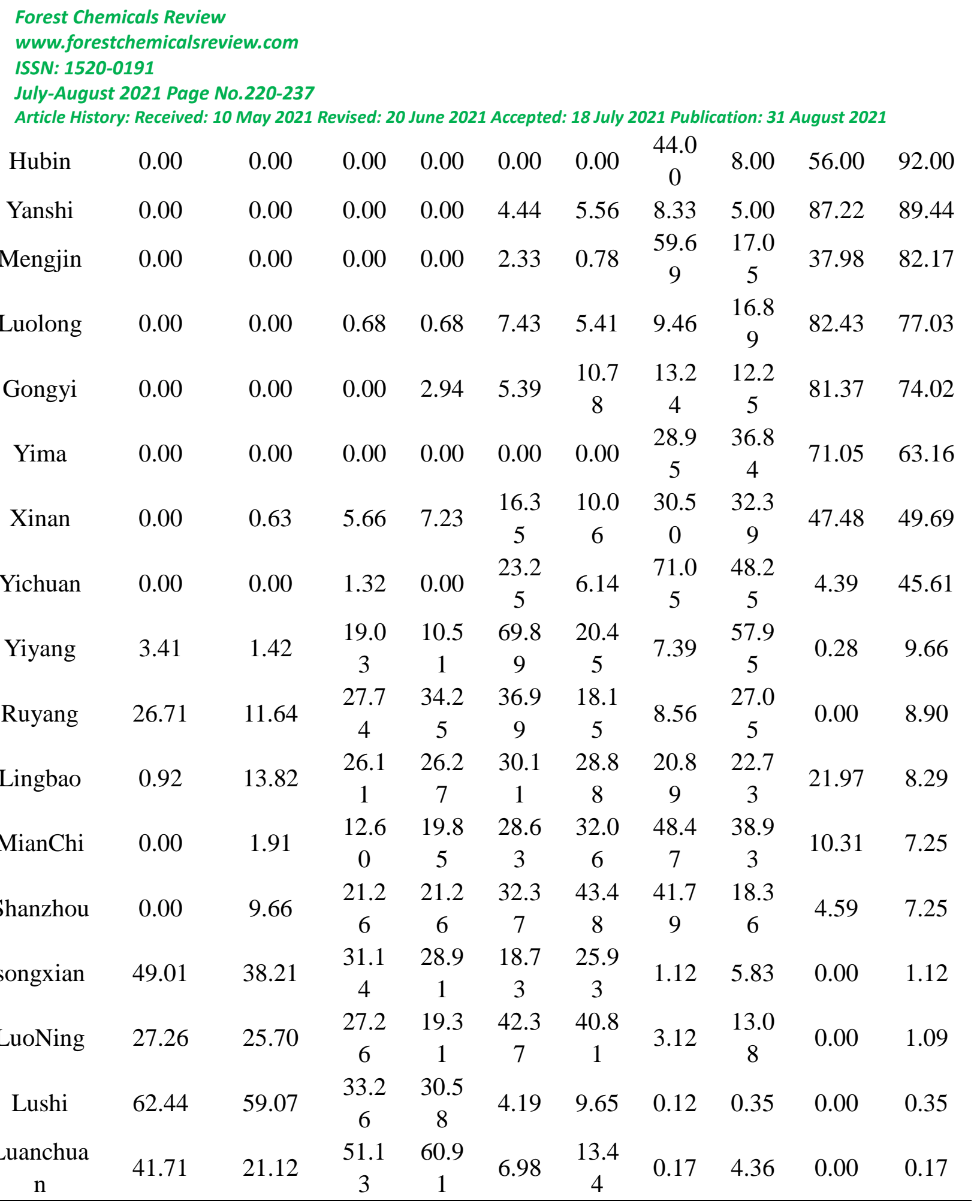


Article History: Received: 10 May 2021 Revised: 20 June 2021 Accepted: 18 July 2021 Publication: 31 August 2021
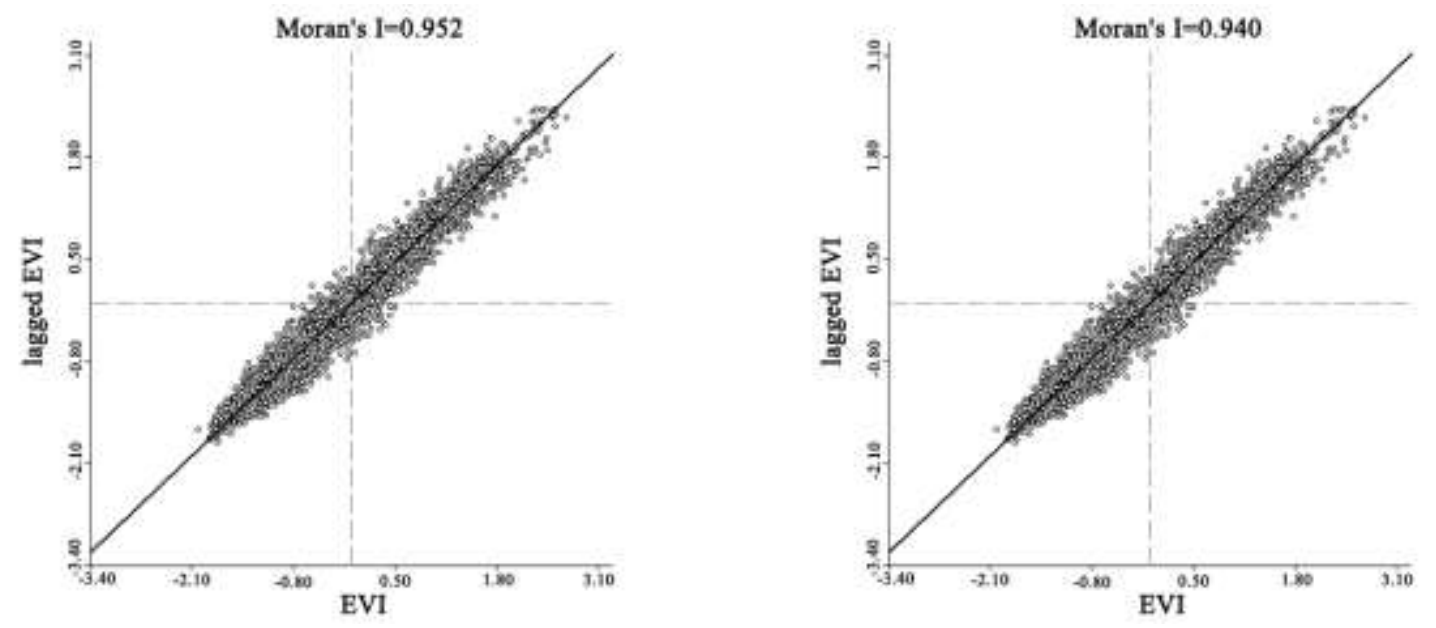

Fig 3: global Moran's I index in western Henan from 2000 to 2019

\subsection{Spatial Agglomeration Characteristics}

The global Moran's I index in 2000 and 2019 is 0.952 and 0.940, respectively, which shows that the ecological vulnerabilities in 2000 and 2019 have obvious spatial autocorrelation and positive correlation (Fig 3). From the LISA cluster diagram (Fig 4), the H-H clustering areas were distributed in extreme vulnerable areas in 2000, concentrated in the northeast and northwest of the study area; L-L clustering areas were distributed in negligible and light vulnerable areas, and concentrated in southern mountainous areas; by 2019, the H-H clustering areas further expanded from the city to the surrounding counties. Especially, the extreme vulnerable area around the main city increased greatly; it is closely related to the rapid expansion of construction land after 2000. The L-L clustering areas were mainly distributed in the southern mountainous areas. Therefore, from 2000 to 2019, the ecological vulnerability was characterized by significant aggregation. The $\mathrm{H}-\mathrm{H}$ clustering areas were mainly distributed in extreme vulnerable areas, while the L-L aggregation areas were mainly related to negligible and light vulnerable areas. 


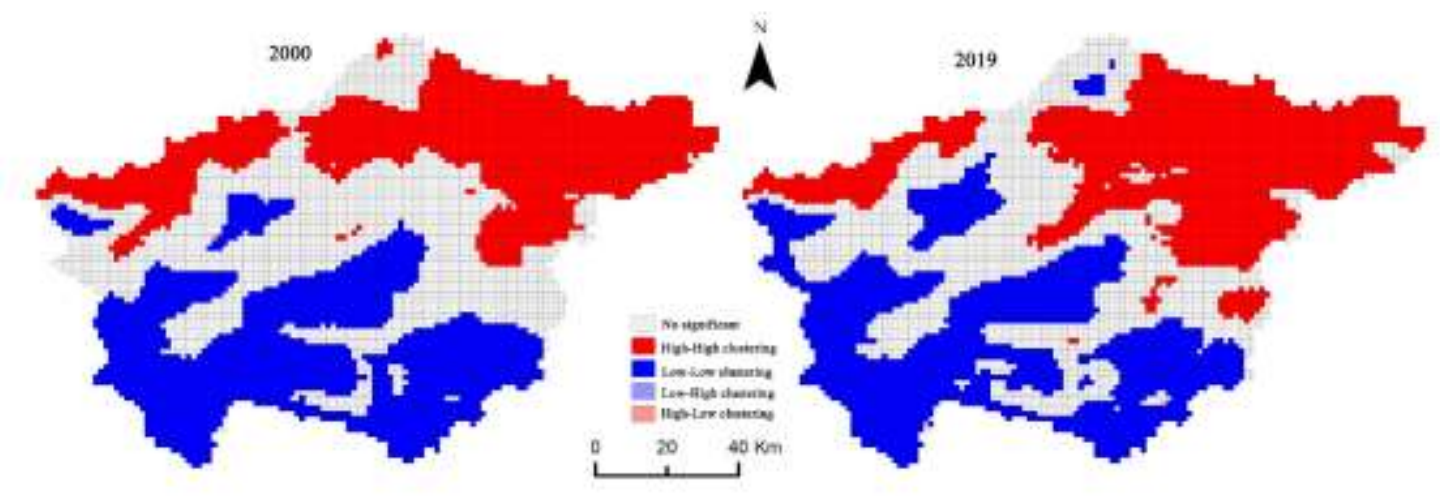

Fig 4: The LISA aggregation of ecological vulnerability in western Henan from 2000 to 2019

\subsection{Driving Factors}

By calculating the principal component load matrix, the information of many original indexes can be reflected in a few principal components, and the main indexes affecting the evaluation results can be highlighted. The closer the absolute value of load coefficient is to 1 , the greater the impact of the driving factor on ecological vulnerability is. It can be seen from TABLE VIII and TABLE IX of calculation results that the first principal component in 2000 has a great correlation with elevation, slope, NDVI, annual mean temperature, terrain relief, degree of land use and land use type, with a contribution rate of $49.205 \%$. These factors mainly reflect the topography, vegetation and climate of the study area, and can be regarded as the principal components of natural background. The $2 \mathrm{nd}$, 3rd and 4th principal components have a great correlation with per capita cultivated land, proportion of the second industry, annual mean precipitation, per capita GDP and landscape diversity, representing the natural and socio-economic development respectively, with contribution rates of $13.327 \%, 11.339 \%$ and $7.581 \%$, respectively.

TABLE VIII. Matrix of principal components in 2000.

\begin{tabular}{ccccc}
\hline EVALUATING INDICATORS & $\mathbf{1}$ & $\mathbf{2}$ & $\mathbf{3}$ & $\mathbf{4}$ \\
\hline Elevation & $-0.9041^{*}$ & 0.0681 & 0.1749 & -0.0422 \\
Slope & $-0.9261^{*}$ & 0.1153 & 0.1244 & 0.1269 \\
index & $0.8966^{*}$ & -0.1494 & -0.0397 & -0.0226 \\
Normalized Difference vegetation & -0.5889 & 0.2753 & $-0.6337^{*}$ & 0.1462 \\
Annual mean precipitation & $-0.8717^{*}$ & 0.1132 & 0.2701 & -0.0409 \\
Annual mean temperature & 0.5507 & 0.5749 & -0.1258 & 0.0979 \\
Population density & & & & $\mathbf{2 3 3}$
\end{tabular}


Article History: Received: 10 May 2021 Revised: 20 June 2021 Accepted: 18 July 2021 Publication: 31 August 2021

\begin{tabular}{ccccc} 
Degree of land use & $0.9037^{*}$ & 0.0484 & -0.0440 & -0.2708 \\
Land use type & $0.9412^{*}$ & -0.0094 & -0.0226 & -0.2006 \\
Per capita cultivated land & -0.0003 & $0.6515^{*}$ & -0.6187 & 0.3044 \\
GDP per capita & 0.3880 & 0.5025 & $0.6933^{*}$ & 0.1349 \\
Landscape fragmentation & 0.5377 & -0.3689 & -0.0420 & 0.5431 \\
Landscape diversity & -0.3739 & 0.4061 & -0.1039 & $-0.7032^{*}$ \\
urbanization rate & 0.5715 & 0.3433 & -0.1872 & -0.0920 \\
Terrain relief & $-0.8311^{*}$ & 0.1374 & 0.1090 & 0.1407 \\
Proportion of the second industry & 0.4385 & $0.6499^{*}$ & 0.4872 & 0.2097 \\
\hline
\end{tabular}

* indicates the evaluation index with higher contribution rate among the principal components.

The first principal component in 2019 has great correlation with elevation, slope, NDVI, annual mean precipitation, annual mean temperature, terrain relief, degree of land use, Land use type and urbanization rate. The contribution rate reached 51.852\%. Compared with 2000, the annual mean precipitation and urbanization rate were increased. Therefore, it is speculated that the ecological environment changes in the study area in recent years have great correlation with urbanization rate and annual mean precipitation. In 2019, the second, third and fourth principal components had great correlation with the per capita ratio of cultivated land, the per capita GDP and landscape diversity. Their contribution rates are $13.325 \%, 9.035 \%$ and $7.378 \%$, respectively.

TABLE IX. Matrix of principal components in 2019.

\begin{tabular}{ccccc}
\hline EVALUATING INDICATORS & $\mathbf{1}$ & $\mathbf{2}$ & $\mathbf{3}$ & $\mathbf{4}$ \\
\hline Elevation & $-0.8888^{*}$ & 0.0646 & 0.0819 & -0.0513 \\
Slope & $-0.8871^{*}$ & 0.1202 & 0.0977 & 0.0715 \\
Normalized Difference & $0.9232^{*}$ & -0.0237 & -0.1208 & -0.0562 \\
vegetation index & & & & \\
Annual mean precipitation & $-0.7921^{*}$ & 0.2560 & -0.3083 & 0.2618 \\
Annual mean temperature & $-0.9137^{*}$ & 0.1167 & 0.0584 & -0.0391 \\
Population density & $0.5451^{*}$ & 0.5064 & -0.2213 & 0.1903 \\
Degree of land use & $0.8981^{*}$ & 0.0434 & -0.1656 & -0.2005 \\
Land use type & $0.9366^{*}$ & -0.0178 & -0.1147 & -0.1496 \\
Per capita cultivated land & $0.0781^{*}$ & $0.6972^{*}$ & -0.3084 & 0.5297 \\
GDP per capita & 0.4300 & $0.6656^{*}$ & 0.5313 & 0.0027 \\
Landscape fragmentation & 0.5158 & -0.4112 & 0.2724 & 0.5416 \\
Landscape diversity & -0.4646 & 0.4124 & -0.3004 & -0.5696 \\
Urbanization rate & $0.6471^{*}$ & 0.3225 & -0.3013 & -0.0258 \\
Terrain relief & $-0.8245^{*}$ & 0.1574 & 0.1083 & 0.0683
\end{tabular}


* indicates the evaluation index with higher contribution rate among the principal components.

\section{CONCLUSIONS}

From 2000 to 2019, the ecological environment in western Henan showed a deteriorating trend as a whole. Extreme vulnerable areas were mainly distributed in the main city and surrounding areas. Strong and medium vulnerable areas were mainly distributed in the loess hilly areas, and negligible and light vulnerable areas were distributed in southern and northern mountainous areas.

From 2000 to 2019, there are obvious differences in the degree of ecological vulnerability in different counties, with the highest degree of ecological vulnerability in the main city and suburban areas, which is always at an extremely vulnerable level. The degree of ecological vulnerability in the low-altitude Loess hilly areas around the northeast main city shows a trend of evolution from medium and strong vulnerability to strong and extreme vulnerability. With the implementation of the project of returning farmland to forest, the vulnerable degree of ecological environment in the loess hilly region in the west of the study area tends to decrease.

The ecological vulnerabilities from 2000 to 2019 have significant positive correlation and aggregation characteristics. The $\mathrm{H}-\mathrm{H}$ clustering areas are mainly distributed in extreme vulnerable areas, while the L-L clustering areas are mainly related to negligible and light vulnerable areas.

The ecological vulnerability in western Henan is formed by natural and human factors, and its driving factors are mainly elevation, slope, terrain relief, degree of land use, annual mean precipitation, NDVI, annual mean temperature, land use type and urbanization rate. The ecological environment changes in the study area from 2000 to 2019 have great correlation with urbanization rate and annual mean precipitation.

Since 2000, with the rapid development of economy, the urbanization process in western Henan has been significantly accelerated, the overall vulnerability of the ecological environment in western Henan has shown a deteriorating trend. Affected by both natural and human activities, the vulnerability degree of low-altitude Loess hilly region in western Henan has changed obviously. Based on the grid micro-scale, this study selected the Loess hilly region in western Henan Province as the research object, and selected 15 indexes from natural background and human disturbance to build an ecological vulnerability evaluation system, trying to provide a theoretical basis for ecological construction and restoration in similar areas. 


\section{REFERENCES}

[1] Ippolito A, Sala S, Faber J H (2010) Vighi M. Ecological vulnerability analysis: a river basin case study. Science of the total Environment, 408(18): 3880-3890

[2] Wang BB, Ding MJ, Guan QH, Ai JH (2019) Gridded assessment of eco-environmental vulnerability in Nanchang city. Acta Ecologica Sinica, 39(15): 5460-5472

[3] Nguyen AK, Liou YA, Li MH, Tran TA (2016) Zoning eco-environmental vulnerability for environmental management and protection. Ecological Indicators, 69: 100-117

[4] De Lange HJ, Sala S, Vighi M, Faber JH (2010) Ecological vulnerability in risk assessment A review and perspectives. Science of the Total Environment, 408(18): 3871-3879

[5] Zhou JH, Huang XX (2008) A review on the assessment methods of ecological vulnerability. Yunnan Geographic Environment Research, 20: 55-60

[6] Ghosh S, Das A (2019) Urban expansion induced vulnerability assessment of East Kolkata Wetland using Fuzzy MCDM method. Remote Sens. Lett., 13: 191-203

[7] Li LW, Liu Z, Bai YL, Sheng J (2018) Environmental vulnerability evaluation of Yellow River Delta coast based on AHP-CVI technology. Ecol. Environ. Sci., 27: 297-303

[8] Wang Y, Ding Q, Zhuang DF (2015) An eco-city evaluation method based on spatial analysis technology: A case study of Jiangsu Province, China. Ecological Indicators, 58: 37-46.

[9] Tapia C, Abajo B, Feliu E, Mendizabal M, Martinez JA, Fernández JG, Laburu T, Lejarazu A (2017) Profiling urban vulnerabilities to climate change: An indicator-based vulnerability assessment for European cities. Ecological Indicators, 78: 142-155

[10] Ma J, Li CX, Wei H, Ma P, Yang YJ, Ren QS, Zhang W (2015) Dynamic evaluation of ecological vulnerability in the Three Gorges Reservoir Region in Chongqing Municipality, China. Acta Ecologica Sinica, 35(21): 7117-7129

[11] Eckert S, Jelinek R, Zeug G, Krausmann E (2012) Remote sensing-based assessment of tsunami vulnerability and risk in Alexandria, Egypt Applied Geography, 32(2): 714-723

[12] Zhao P, HE Hongming, Yang F, Li BT, Zhang L, Zhang JH, WEI C, Yang SG (2020) Study on Environmental Vulnerability Assessment of Reservoir Area. Yellow River, 42(12): 85-87

[13] Qiao Z, Yang X, Liu J, Xu XL (2013) Ecological vulnerability assessment integrating the spatial analysis technology with algorithms: a case of the woodgrass ecotone of Northeast China. Abstract and Applied Analysis, 2013: 1-8

[14] Du J, Zhao SC, Qiu SK, Guo L (2021) Land Use Change and Landscape Ecological Risk Assessment in Loess Hilly Region of Western Henan Province from 2000 to 2015. Research of Soil and Water Conservation, 28(1): 279-291

[15] Feng YX, Luo G P, Yin CY (2009) Change of Land-Use Degree and Ecological Security Assessment of Inland River Basins in the Arid Area-A Case Study on Manas River Basin in Xinjiang. Journal of natural resources, 24(11): 1921-1932

[16] Qiu W, Zhao QL, Li S, Chang CC (2008) Ecological Security Evaluation of Heilongiiang Province with Pressure-State-Response Model. Environmental Science, 29(4): 1148-1152

[17] Tong C (2000) Review on Environmental Indicator Research. Research of Environmental Science, 13(4): 53-55 
Forest Chemicals Review

www.forestchemicalsreview.com

ISSN: 1520-0191

July-August 2021 Page No.220-237

Article History: Received: 10 May 2021 Revised: 20 June 2021 Accepted: 18 July 2021 Publication: 31 August 2021

[18] Guo B, Kong WH, Han F, Wang JJ, Jiang L, Lu YF (2018) Dynamic monitoring of ecological vulnerability in the semi-arid desert and steppe ecological zone of Northern China based on RS and its driving mechanism analysis. Tropical Subtropical Bot, 26: 1-12 